\title{
Seleção Brasileira de Handebol Feminino: da primeira convocação à conquista da vaga Olímpica (1983-2000)
}

\author{
Suélen de Souza Andres* \\ ORCID iD 0000-0002-6499-824X \\ Centro Universitário Católica do Leste de Minas Gerais, Educação Física, Ipatinga, Brasil
}

\author{
Silvana Vilodre Goellner* \\ ORCID iD 0000-0002-1990-665X \\ Universidade Federal do Rio Grande do Sul, Escola Superior de Educação \\ Física, Fisioterapia e Dança, Porto Alegre, Brasil
}

\begin{abstract}
Resumo: Fundamentado no aporte teórico-metodológico da História Oral, este artigo analisa a trajetória inicial da Seleção Brasileira de Handebol Feminino desde sua primeira formação até a conquista da primeira vaga olímpica (1983-2000). Para tanto, foram realizadas seis entrevistas, sendo cinco com ex-atletas da Seleçâo e uma com um ex-técnico, as quais foram cotejadas com fontes documentais. A partir das análises, foi possível evidenciar que o início da Seleção se deu motivado pelo surgimento de competiçóes continentais classificatórias para os Jogos Olímpicos e o Campeonato Mundial. No que diz respeito ao seu desenvolvimento, percebemos que o movimento de se aproximar do handebol europeu, por meio dos intercâmbios, foram significativos para alcançar a hegemonia da modalidade no continente americano e adentrar nos Jogos Olímpicos.
\end{abstract}

Palavras-chave: Handebol. Mulheres. Jogos Olímpicos. Seleção Brasileira.

Doutora em Ciências do Movimento Humano pela Universidade Federal do Rio Grande do Sul (UFRGS). Professora do curso de Educação Física do Centro Universitário Católica do Leste de Minas Gerais (UNILESTE). E-mail: suelenandres@yahoo.com.br.

* Doutora em Educação pela Universidade Estadual de Campinas (Unicamp), com pós-doutorado pela Faculdade do Desporto da Universidade do Porto, em Portugal. Professora Titular da Escola Superior de Educação Física, Fisioterapia e Dança (ESEFID) da Universidade Federal do Rio Grande do Sul (UFRGS). E-mail: vilodre@gmail.com. 


\title{
Brazilian Women's Handball Team: from the first call-up to winning the Olympic spot (1983-2000)
}

\begin{abstract}
Based on the theoretical-methodological contribution of Oral History, this article analyzes the initial trajectory of the Brazilian Women's Handball Team from its first formation until the first Olympic spot (1983-2000). To this end, six interviews were conducted, five with ex-athletes from the national team and one with a former coach, which were compared with documentary sources. From the analysis, it was possible to show that the beginning of the national team was motivated by the emergence of continental qualifying competitions for the Olympic Games and the World Championship. With regard to its development, we realized that the movement to get closer to European handball, through exchanges, were significant to achieve the hegemony of the sport in the American continent and to enter the Olympic Games.
\end{abstract}

Keywords: Handball. Women. Olympic Games. Brazilian Team.

\section{Introdução}

O handebol, nos moldes como o conhecemos hoje, passou a fazer parte da cultura esportiva brasileira na década de 1950 . O processo de disseminaçáo da modalidade começou a partir de um curso ofertado pelo professor francês Augusto Listello, na Associação dos Professores de Educação Física (APEF) na cidade de Santos (SP) em 1952. Com a participaçáo de professores oriundos de todo território nacional (Reis, 2018), o esporte passou a se desenvolver em diversas cidades brasileiras, tendo a escola como lócus principal desse processo. A consolidaçáo do handebol no espaço escolar possibilitou que ele figurasse no rol das modalidades disputadas tanto nos Jogos Estudantis Brasileiros (JEBs), inseridos em 1971, como nos Jogos Universitários Brasileiros (JUBs), a partir de 1972 (Hubner; Reis, 2005).

Fora do contexto escolar, a primeira competição que encontramos algum registro foi o Campeonato Brasileiro Juvenil, cuja primeira edição ocorreu em 1973 sob a organizaçăo da Confederação Brasileira de Desportos (CBD). É ainda nessa década que as mulheres começam a disputar o handebol nos Jogos Olímpicos, mais especificamente na edição de 1976, realizada em Montreal, Canadá. Os homens iniciaram nos Jogos Olímpicos em 1972, quando a modalidade passou a fazer parte do cronograma olímpico. Entretanto, a seleçâo brasileira de mulheres, foco deste estudo, só conquistaria uma vaga olímpica em 2000.

No âmbito da seleção, o handebol brasileiro chega ao seu ápice em 2013, após a conquista da inédita medalha de ouro no XX Campeonato Mundial de Handebol, ocorrido na Sérvia. As falas "Ninguém acreditava, mas o Brasil é campeão Mundial!", "A vitória da superação!" e "Vitória de quem não dava nada para essas meninas!" indicavam o caráter inesperado do título, especialmente por parte daqueles/as que náo vivenciam a modalidade. A importância e o ineditismo fizeram desse momento um 
dos mais lembrados e visibilizados na história da modalidade. Essa ocasião pode ser revista e rememorada a partir de alguns artefatos que retrataram essa conquista, entre os quais destaco os livros "Raça, Brasil: os bastidores da conquista inédita do Mundial de Handebol" (2014) e "A história por trás da glória: o Mundial de Handebol 2013" (2015), e o documentário "Meninas de ouro" (2016).

A atenção dada ao feito se justifica. Pode-se dizer que esse acontecimento marcou a história do handebol brasileiro. Chama atenção, todavia, o quão escassos e pouco conhecidos são os registros - publicaçóes, documentos, narrativas, memórias - sobre o início desse percurso, que poderiam ampliar o conhecimento sobre a trajetória da Seleçấo Brasileira de Handebol, em especial sobre os acontecimentos anteriores à conquista do Mundial.

Diante do apagamento ou da inexistência de muitas fontes que registram a prática de handebol no Brasil, pouco se conhece sobre a história da Seleção Brasileira de Handebol Feminino e, consequentemente, a história da própria modalidade. Tendo em vista esse panorama e com o intuito de contribuir no preenchimento de algumas lacunas sobre a história da Seleção, neste estudo nos propomos analisar a trajetória da Seleção Brasileira de Handebol desde sua primeira convocação até a conquista da primeira vaga olímpica (1983-2000).

Para tanto, nos apropriamos do referencial teórico -metodológico da História Oral (Thompson, 1992; Ferreira; Amado, 1996; Alberti, 2010), por compreendermos que tal perspectiva permite analisar, por meio das fontes orais, aspectos relacionados à constituição e estruturação da seleção.

Tendo as narrativas como fontes privilegiadas deste estudo, as mesmas foram realizadas de acordo com os procedimentos previstos no projeto "Garimpando Memórias", contemplando as etapas de elaboração do roteiro, realização de entrevista, transcrição, copidesque, conferência por parte da pessoa entrevistada, assinatura da carta de cessão dos direitos autorais e publicação do texto on-line. Dito isso, foram entrevistadas as ex-atletas Elza Giovanelli Balan, Margareth Pioresan, Soraya Novaes da Silva, Maria José Batista de Sales, Maria Aparecida dos Santos e o ex-técnico Francisco de Assis Farias.

Da análise do material empírico que ancora este estudo, foram identificados dois aspectos centrais como sendo aqueles que possibilitaram a criaçáo e desenvolvimento da Seleção Brasileira de Handebol Feminino no seu princípio: o surgimento de competiçóes continentais e os intercâmbios europeus.

\section{3 - A primeira convocação}

As principais competiçôes do handebol de seleçôes são o Campeonato Mundial de Handebol (CMH), que teve sua primeira edição em 1957, havendo a criação da 
série B - uma "segunda divisão" - em 1977, e os Jogos Olímpicos (JOs), que teve a primeira disputa em 1976. As seleçóes do continente americano, contudo, só ingressam nesse circuito, de forma sistemática, a partir da década de 1980, quando foram criadas as competiçóes continentais que servem como classificatórias para os JOs e o CMH. A primeira delas aconteceu em Buenos Aires, Argentina, entre os dias 9 e 13 de novembro de 1983: o I Campeonato Sul-Americano de Handebol, para mulheres e homens (Krastev, 2021a).

De acordo com as fontes consultadas, é em função dessa competição que acontece a criação da Seleção Brasileira de Handebol (Francisco de Assis Farias, 2019; Soraya Novaes da Silva, 2019; Margareth Pioresan, 2015). Soraya Novaes da Silva, uma das jogadoras dessa seleção pioneira, relembra essa primeira convocação:

Minha convocação se deu em 1983. A gente tinha ido para um campeonato, uma Copa Brasil, eu tinha sido destaque no campeonato e fui artilheira do campeonato. Aí o William do Rio, William, o Leonir e convidaram o Elói também para fazer parte da comissáo técnica lá no Rio de Janeiro, formou a primeira seleção brasileira, era tudo novidade. Sorte para eles, que ninguém tinha nada, a gente ia defender o Brasil no Sul-Americano, na Argentina [...]. (Soraya Novaes da Silva, 2019).

A participaçáo do selecionado brasileiro no evento foi acompanhada pelo jornal O Estado de Sáo Paulo, que noticiou o início do campeonato, o jogo de estreia, assim como os resultados obtidos pelas equipes de homens e mulheres (Handebol..., 1983; Handebol..., 1983a; Handebol..., 1983b; Brasil..., 1983a; Brasil..., 1983b).

Em sua primeira competição, a seleção não demonstrou ter dificuldades em passar pelas outras equipes participantes, como é possível observar pelos resultados, todos vitoriosos: 27 a 3 contra o Paraguai, 45 a 5 contra o Chile, 30 a 5 contra o Uruguai. e, na final, 18 a 9 frente à anfitriá Argentina (Krastev, 2021a). A conquista do seu primeiro ouro lhe garantiu vaga em dois importantes eventos: o Pré-Olímpico, que aconteceria em Los Angeles no ano seguinte, e o I Campeonato Pan-Americano de Handebol, que iria ocorrer em 1986. Ambos, por sua vez, eram seletivos para os dois maiores eventos da categoria, os Jogos Olímpicos e o Campeonato Mundial de Handebol, respetivamente.

Comandada pelo técnico William Felippe - professor da Universidade Gama Filho (UGF) e técnico da equipe de handebol do Flamengo -, auxiliado pelos professores Elói Zamberlam - técnico da Universidade Estadual de Londrina (UEL), da Seleção do Paraná e da equipe Incolustre/Cambé -, Walmir Prado de Alencar técnico da Seleção Amazonense de Handebol - e Leoni Nascimento - professor da Pontifícia Universidade Católica do Rio de Janeiro (PUC-RJ), técnico de handebol do Flamengo e diretor de handebol da Confederação Brasileira do Desporto Universitário (CBDU) -, essa seleção era representada por atletas do Paraná, Rio de Janeiro, Sáo Paulo, Amazonas e Santa Catarina (Sueli..., 1983). 
A escolha de William para ser o técnico teve como influência sua proximidade com o então presidente da Confederação Brasileira de Handebol (CBHb), o professor José Maria Teixeira. William menciona que o fato de ambos terem sido colegas de turma no curso de Educaçáo Física e terem trabalhado juntos por um ano em um colégio do Rio de Janeiro pode ter facilitado e influenciado a sua indicação para a função (Felippe; Caldas, 2020).

O local definido para a preparação da seleção foi o Centro de Educação Física Almirante Adalberto Nunes (Cefan), pertencente à Marinha do Brasil, na cidade do Rio de Janeiro (RJ), estado de atuação do técnico William. Sobre a experiência desses treinamentos, Soraya, conta:

O treinamento era dado pelo William, em comum acordo com o Leonir e o Elói. Era assim, tudo meio novidade para todo mundo, porque a gente náo conhecia muito as pessoas, e assim, a escola de handebol que o Paraná tem é bem diferente do resto dos outros países, dos outros estados. A gente encontrou bastante dificuldade porque nós éramos bem regradas em cima de jogadas, e os outros times, então saía só uma ou duas porque eram destaque. Não saíam, nós fomos em quase cinco do Paraná para lá. A gente tinha mesmo uma base de aplicação técnico/tático correta, movimentaçáo de defesa correta, entáo isso foi um marco para mim, bastante grande, porque a gente era tudo certinha, corria bem, fazia bem, arremesso podia, só podia arremessar quando o técnico falava que podia arremessar, e tudo mais, e lá era uma coisa mais individualista, então isso foi uma coisa que marcou bastante. (Soraya Novaes da Silva, 2019).

As variaçóes mencionadas na forma de treinar e jogar handebol podem decorrer do fato de a comissão técnica e as jogadoras virem de diversos estados do Brasil, talvez seguindo diferentes escolas de treinamento e de jogo. Como náo encontrei muitas informaçóes acerca da existência de competiçóes entre equipes de diferentes regióes do país, o que geraria intercâmbios de experiências, fica difícil alguma afirmação nesse sentido. De acordo com as fontes, as competiçôes em nível nacional existentes na época eram: o Campeonato Brasileiro Adulto de Handebol, criado em 1978 (Hubner; Reis, 2005; Reis, 2018) e realizado de dois em dois anos (Baptilani, 2005), a Taça Brasil de Clubes, evento anual, tendo sua primeira edição em 1982 (Baptilani, 2005) e os Jogos Universitários Brasileiros, existentes desde 1972 (Hubner; Reis, 2005).

Outro ponto destacado na fala de Soraya foi suas impressôes em relação ao evento:

[...] o campeonato da Argentina foi bem marcante, que a gente ficou em um, não sei nem explicar como que era o lugar, parecia umas tendas, e era uma comida ruim, bebida ruim, os jogos eram em um lugar ruim, era bom porque tudo era novidade, mas não foi um campeonato de dizer assim, ah foi um Sul-Americano digno do que é hoje uma competição. Bem precário mesmo. (Soraya Novaes da Silva, 2019). 
Na volta para o Brasil, uma reportagem veiculada pela Folha de São Paulo ganha destaque ao expor denúncias de atletas contra o técnico William. Em ambas, o título possuía o nome da atleta porta-voz das denúncias. Publicada em 18 de novembro de 1983 sob o título "Sueli faz pesadas críticas ao técnico William Felippe", a matéria relata o que a atleta denomina de "antipatia mútua" entre ela e o técnico. Suas críticas faziam referência a não convocaçáo de determinadas jogadoras para compor o elenco que foi a Buenos Aires, que em seu entendimento não poderiam ter ficado de fora (Sueli..., 1983). Para além disso, a atleta relata uma conduta autoritária e hostil do técnico em relação às jogadoras:

Eu não devia contar, mas agora vou até o fim: um dia, reunido com as jogadoras, disse, aos gritos, que éramos um bando de retardadas e quem não gostasse que fosse embora. Foi o que fiz. Infelizmente, não deu para segurar as lágrimas. (Sueli..., 1983, p. 23).

A mesma visão sobre o técnico é compartilhada pela ex-atleta Soraya Novaes ao comentar:

É, mas ele fala isso [...] a gente não podia nem falar nada, ele falava, você obedecia, [...] como a gente não tinha muito conhecimento da pessoa e tudo mais, a gente respeitava, mas ele era muito autoritário [...]. (Soraya Novaes da Silva, 2019).

E por fim, a jogadora faz críticas ao trabalho dele, que em sua opinião tem um viés muito teórico e que "no esporte, inclusive, a prática suplanta a teoria" (Sueli..., 1983, p. 23). Novamente emergem diferenças sobre as experiências com a modalidade, aqui materializada nos conhecimentos que o técnico compartilhava.

William, ao falar de sua experiência como técnico, sem fazer referência direta às críticas recebidas na época, enfatiza seu empenho em adquirir conhecimentos atualizados sobre handebol. Em suas palavras, "já conhecia todos os tipos de defesa e ataque, aqueles mais simples que apareciam nas apostilas" (Felippe; Caldas, 2020). E, ainda, destaca a dificuldade que teve em trabalhar com o grupo, especialmente com as jogadoras cujo técnico do clube ao qual pertenciam fazia parte da comissáo. $\mathrm{O}$ extécnico relata que as atletas seguidamente se dirigiam ao "seu" técnico, e caso William passasse alguma atividade técnica e/ou tática diferente das que conheciam, as jogadoras argumentavam que "seu" técnico trabalhava de outro modo e em alguns momentos se recusavam a realizar (Felippe; Caldas, 2020).

Mesmo diante dos impasses existentes, a história da Seleção Brasileira de Handebol estava iniciada, e sua participaçáo e conquista do ouro no I Campeonato SulAmericano de Handebol já dava indícios de que o handebol brasileiro se encontrava mais desenvolvido em relação aos demais países sul-americanos.

Com a saída do técnico William Felippe, no fim de 1983, Elói Zamberlan sai da 
posição de auxiliar e passa a técnico principal da seleção, permanecendo até meados de 1985, quando assume em seu lugar o alagoano Francisco de Assis Farias (Shyko). Elói retorna ao comando da seleção em 1989 e encerra seu ciclo em 1991.

Em 1984, a segunda edição do Campeonato Sul-Americano de Handebol teve como sede a cidade de Caxias do Sul(RS), entre os dias 4 e 8 de dezembro (Krastev, 2021b). A seleção novamente não encontrou dificuldades e conquistou, de forma invicta, o bicampeonato na competição. Com Elói à frente da seleção, nota-se que a equipe Incolustre/Cambé do estado do Paraná - também comandada por Elói compóe a sua base, mantendo-se assim por toda década de 1980.

Em 1985, não havia competiçóes para a categoria adulta, mas, com a criação do I Torneio Sul-Americano de Handebol Júnior, ocorrido em Montevidéu, Uruguai, entre os dias 2 e 7 de outubro, a CBHb convoca a primeira Seleçáo Brasileira de Handebol Júnior, que comporta atletas com idades entre 18 e 20 anos. Essa informação ganha relevância, pois, das 12 atletas convocadas, cinco já atuavam pela seleção adulta Adalgiza Mafra Moreno (Gica), Eliane Alvim Dias, Elza Giovaneli, Kelma Moreno Melo Silva e Vânia Aparecida Marcolini Zacarini - todas jogadoras do Incolustre/ Cambé. A comissão técnica era composta pelo professor Francisco de Assis Farias (Shyco), de Alagoas, auxiliado por Alexandre Cerqueira Pereira, de Sergipe. Shyco, inclusive, viria assumir a seleção adulta entre os anos de 1986 e 1988.

Em 1986, o Brasil novamente se torna sede de competiçóes internacionais de handebol. Entre os dias 20 e 25 de agosto, na cidade de Novo Hamburgo (RS), foi realizado o III Campeonato Sul-Americano de Handebol, sendo a segunda vez consecutiva que o evento ocorre no país. Na mesma cidade, aconteceu I Campeonato Pan-Americano de Handebol, e, simultaneamente, o evento classificatório para o Campeonato Mundial de Handebol (Krastev, 2021c; Krastev, 2021d).

A equipe brasileira, mais uma vez, não encontrou dificuldades e conquistou o tricampeonato Sul-Americano de Handebol de forma invicta, ao passar pelas equipes da Argentina (18 x 5), Uruguai (29 x 7) e Paraguai (27 x 17) (Krastev, 2021d), efetivando, assim, sua hegemonia no continente sul-americano. Todavia, é no I Campeonato PanAmericano que a seleção brasileira sofreu a primeira derrota desde sua criação, diante dos Estados Unidos (26 x 17) e, posteriormente, para o Canadá (24 x 18). Ao perder esses dois jogos, o Brasil finaliza sua participação na competição em terceiro lugar (Krastev, 2021c), garantindo, assim, vaga para sua estreia no Campeonato Mundial de Handebol B, marcado para acontecer na Bulgária no ano seguinte.

O handebol dos Estados Unidos e do Canadá só seriam superados pela seleção brasileira em 1997, na quarta edição do Campeonato Pan-Americano, realizado em Poços de Caldas (MG). Uma vez vencidas as duas equipes, o Brasil só perderia novamente sua invencibilidade em competiçóes do continente americano no ano de 2009, quando foi derrotada pela Argentina no X Campeonato Pan-Americano de Handebol, realizado em Santiago, Chile. 


\section{6 - 0 primeiro intercâmbio}

A primeira experiência de intercâmbio internacional envolvendo a seleção brasileira, por meio de um estágio realizado na Alemanha, ocorreu em 1986. Com uma permanência de três semanas no país de destino, durante o dia, as atletas participavam de atividades e treinamentos relacionados às questôes técnicas e táticas do handebol, e à noite participavam de reuniôes com os técnicos e professores alemães para discutir suas aprendizagens. A seleção também realizou alguns jogos amistosos. Na volta, tiveram a incumbência de repassar os ensinamentos aprendidos para outras atletas (Francisco de Assis Farias, 2019). Soraya relembra os ensinamentos que recebeu da colega Eliane:

[...] Eliane foi na primeira viagem para a Alemanha, foi quando veio com a técnica da finta de braço. Lá eles tinham um acessório para treinamento tipo um pirulito, um cano enfiado em um pedestal de concreto que você tinha que passar por aquilo lá sem mexer o cano. Ela observou lá nos treinos e trouxe para Cambé, a princípio, depois a gente levou para a seleção, isso foi uma coisa que ela, pessoa que observava muito, e tinha o poder de guardar aquilo e conseguir transmitir para a gente. Ela trouxe bastante coisa, bastante novidade em relação a isso, arremesso quicado, tem gente que não fazia antes, então teve muita coisa, técnicas, e ela trouxe para a gente e a gente começou a melhorar em relação a isso. (Soraya Novaes da Silva, 2020).

O ex-técnico Shyco Farias, que participou de três intercâmbios na Alemanha (1986. 1987, 1988), relata em sua entrevista que a primeira ida tinha como objetivo preparar a seleção para o I Campeonato Pan-Americano de Handebol. A ex-atleta Soraya, que náo chegou a participar desse primeiro intercâmbio, reconhece a importância que teve os estágios.

Quando [...] o Shyko e o Alexandre assumiram a seleção, já veio uma outra imagem de equipe. [...] já começou a trabalhar em cima do que ele via na Alemanha, porque ele também foi para lá, então deu uma evoluída boa. Mas ficou muito boa a seleção quando a gente começou a fazer mais viagens para o exterior, aí que começou a andar realmente. (Soraya Novaes da Silva, 2019).

As inovaçôes propostas por Shyco e Alexandre, a partir de seus aprendizados nos intercâmbios, não foram bem aceitos em um primeiro momento. Em uma carta enviada, em 1989, pela atleta Eliane Alves Dias ao técnico Francisco de Assis Farias, a jogadora, ao relatar sua trajetória como técnica da equipe de homens da cidade de Cambé (PR), menciona estar seguindo a linha de treinamento da seleção - aquela aprendida na Alemanha e utilizada no I Campeonato Sul-Americano de Handebol, em 1986 - e, assim como ele, sofrendo duras críticas pelo método adotado. Ao se manter firme em suas escolhas e obtendo bons resultados - terceiro lugar nos Jogos 
da Juventude e campeá paranaense em 1988 - sentia necessidade de compartilhar a experiência. Em suas palavras: "Queria dividir isto com alguém que também tivesse sofrido todas as críticas no Pan em Novo Hamburgo, onde disseram que o 3:2:1 não era realidade brasileira" (Dias, 1989, p. 1).

Com a entrada do handebol no programa dos Jogos Pan-Americanos, em 1987, a competiçáo passa ser o evento classificatório do continente americano para os Jogos Olímpicos. Com participação garantida da seleção brasileira, o ano de 1987 destacase pela estreia do selecionado no Campeonato Mundial de Handebol Grupo B e pela chance dupla de poder conquistar uma vaga nos Jogos Olímpicos de Seul (1988), já que o ouro em ambos os eventos garantia vaga nos Jogos.

Mesmo subindo ao pódio em todos as competiçóes que já havia participado, com um aproveitamento próximo aos $90 \%$, as expectativas sobre sua estreia nos $\mathrm{X}$ Jogos Pan-Americanos eram baixas. Em nota publicada pelo jornal $O$ Globo, a qual discorria sobre as possibilidades de medalhas do Brasil, as expectativas sobre a Seleçáo Brasileira de Handebol foram resumidas na expressão "[...] já terão lucro na experiência adquirida [...]” (As estrelas..., 1987). O Brasil não levou o ouro, como já previa o jornal, entretanto, subiu ao pódio ao conquistar o bronze, perdendo somente para as equipes dos Estados Unidos ( $28 \times 16)$ e do Canadá $(22 \times 17)$.

Em sua estreia no Campeonato Mundial de Handebol Grupo B, ocorrido entre os dias 9 e 18 de dezembro de 1987, na Bulgária, o Brasil ficou na penúltima (15a posiçáo, acima somente da equipe sobre a qual conquistou sua única vitória, a Costa do Marfim (Krastev, 2021e). O baixo aproveitamento da seleção na categoria B do Mundial indicava que o seu desempenho, competente para garantir a hegemonia no continente sul-americano, ainda não era suficiente para ser competitiva em nível mundial e, principalmente, para enfrentar equipes europeias - mesmo as de "segundo nível" - como indicavam os placares das partidas disputadas.

Nos anos seguintes, até o início da década de 1990, a seleção manteve sua invencibilidade ao conquistar o tetra no IV Campeonato Sul-Americano de Handebol (1988), realizado em Assunção, Paraguai. No II Campeonato Pan-Americano (1989), em Colorado Springs, EUA, com Elói Zamberlan novamente como técnico, a seleção replicou o feito realizado em 1986 ao conquistar a medalha de bronze, perdendo novamente somente para os Estados Unidos e o Canadá.

Ainda em 1989, em sua segunda participação no Campeonato Mundial de Handebol Grupo B, o Brasil repetiu sua classificação $\left(15^{\mathrm{a}}\right)$ ao vencer somente a seleção de Portugal por um gol de diferença (17 x 16) - sua primeira vitória em cima de uma equipe europeia em competiçóes oficiais (Krastev, 2021f).

Ao entrar na década de 1990, mais especificamente no ano de 1991, a seleçáo parte em direção a um novo intercâmbio, dessa vez com destino à Rússia. De acordo com as ex-atletas Elza e Maria, esse estágio estava vinculado a uma formação em Treinamento Desportivo pela Universidade de Moscou, da qual o preparador físico da 
seleção, Antônio Carlos Gomes, iria participar. O profissional, que já havia realizado uma formação em atletismo naquele país em 1990, articulou junto às entidades brasileiras e russas para que a equipe nacional o acompanhasse e servissem de sujeitos à intervençáo que ele realizaria a partir do curso. Nas palavras das atletas:

$\mathrm{Na}$ época se tinha muita dificuldade de intercâmbio. Foi através dele que a gente conseguiu estágio lá [...] nós fomos, como é que eu vou te falar, eu chamo de cobaia, mas é muito feio falar isso, fomos tudo dele, e ele nos levou para a Rússia, lá ele conseguiu um treinador, acho que tinha passado pela seleçáo nacional lá também, ele era um dos melhores, para a gente aprender lá, fisicamente, tecnicamente lá com a Rússia. Nos ajudou muito, fizemos amistoso com outros países, entáo foi assim o que nos ajudou muito [...]. (Elza Giovanelli Balan, 2019).

Quando nós fomos em Moscou [...] foi realmente um trabalho em equipe. Quem fez esse intercâmbio foi Antônio Carlos Gomes. [...]. Foi ele quem fez esse intercâmbio de Brasil e Moscou. Nós fomos utilizadas, trabalhadas, adaptadas ao atletismo pra poder disputar um Pan-Americano e a gente tinha que aprender o estilo Europeu. (Maria Aparecida dos Santos, 2018).

A viagem para Rússia tinha como principal intuito colocar as jogadoras em contato com o estilo de jogo europeu. Para isso, receberam treinamentos do técnico russo, campeão mundial, Larin Georguy Ivanovich, além de participar de um torneio internacional. Antes de embarcarem, as atletas tiveram uma preparação prévia, principalmente física, entre os meses de março e julho, nas cidades de Cambé, Maringá e Londrina. (Maria Aparecida dos Santos, 2018).

Sobre os treinamentos, as atletas sublinham:

Era diferente porque nós aprendemos a jogar um estilo bem no 4-2 que a Rússia... principalmente, porque o nosso treinamento foi exclusivamente pelo técnico russo. [...] Aprender, melhorar o condicionamento físico, ganhar experiência, fizemos vários amistosos com equipes, inclusive masculinas, e também participamos desse torneio mundial lá dentro. Foi muito puxado porque nós passávamos de quase 10 horas de treinamento diário. [...] a gente acordava seis horas da manhã e ia pra esse campo. Era um campo mesmo, de treinamento, porque as repúblicas ainda não eram divididas, então a gente treinava duas horas sem parar. Sem parar! Pra beber água ia trotando. Arremessava a bola, ia trotando. Então já melhorava o condicionamento físico, depois tinha reposição da musculatura, almoçávamos, cochilávamos e voltávamos. [...] Quando a gente retornava já era à noite. Foi muito cansativo, a gente só tinha o sábado e o domingo de folga. (Maria Aparecida dos Santos, 2018).

[...] Ele era fantástico (treinador russo), e assim, ele tirava de você o seu melhor, 
você é uma boa arremessadora de nove metros com extensão, você ia arremessar nove metros com extensão, uma boa arremessadora de nove metros com apoio, você ia priorizar o apoio, entendeu? Então ele assim, ele mostrou para cada uma de nós, o que que era para a gente explorar em cima dos nossos treinamentos. Isso foi uma coisa que foi muito marcante na minha vida. (Soraya Novaes da Silva, 2019).

Para as atletas, essa imersão no handebol russo mudou significativamente sua percepção em relação à modalidade e suas potencialidades, fazendo com que houvesse uma evolução no handebol brasileiro (Soraya Novaes da Silva, 2019). Para Maria, essa experiência foi a semente para que o handebol brasileiro pudesse chegar aonde chegou - fazendo referência às conquistas mais recentes da seleção.

Mesmo reconhecendo os significativos aprendizados obtidos no estágio realizado na Rússia, a experiência teve momentos que marcaram negativamente algumas atletas. Para Elza, o tempo no país não foi dos melhores: “[...] eu bebi água com terra, comi alpiste. $\mathrm{Na}$ Rússia, não dá para falar, porque é muito desumano. Eu treinava machucada. Nós sofremos muito" (Elza Giovanelli Balan, 2019). Outra dificuldade vivenciada diz respeito ao momento de retornar ao Brasil porque, quatro dias após a saída da seleção do país, ocorreu uma tentativa de golpe de estado na União Soviética. As atletas presenciaram e sentiram, assim, os momentos de tensão que antecederam esse episódio.

[...] já tinha passado muito perrengue na verdade, já tinha ficado quarenta e cinco dias em Moscou, de treinamento na Rússia, na época ainda era União Soviética, a gente ficou preso lá, não conseguia voltar, entendeu, foi na época que estourou lá a divisão, e a gente estava lá, simplesmente fomos com a passagem e ficamos lá treinando. (Maria José Batista Sales, 2019).

A gente nem voltava, e a gente saiu um dia antes da guerra. Foi assim, foi a melhor e a pior experiência da vida de todas nós, foi muito traumático. A gente estava em um lugar onde a gente não sabia como a gente ia sair, e assim, cheirava alguma coisa que acontecer muito, muito ruim. No aeroporto de Moscou ficamos, sei lá, umas quatro ou cinco horas esperando o voo. As pessoas todas agitadas [...] 'Eu não quero morrer aqui.' Vim desesperada, chorava, tanto que quando a gente chegou em [...] Aracaju, desci do avião e beijei o chão, de tanto medo e pavor que eu passei naquela cidade. (Soraya Novaes da Silva, 2019).

Para você ter uma ideia, a última vez que eu fui para a Rússia, nós saímos em um dia, dali três dias aconteceu aquela Revolução lá que mudou tudo sabe? Por três dias nós não ficamos, nós íamos ficar presos lá. (Soraya Novaes da Silva, 2019).

Em relação aos custos da viagem, quando questionadas, Maria e Soraya divergem em suas narrativas. Os trechos de suas entrevistas, são ilustrativos para evidenciar essas diferentes percepções. 
Nenhum. Nenhum. Inclusive as nossas passagens de volta da Rússia, a gente teve que... comida, essas coisas, a gente teve que arcar tudo porque náo sei qual foi o rolo na época, que as nossas passagens não foram compradas. Aí o Carlinhos do Rio voltou para o Brasil para tentar levantar uma grana para poder pagar as nossas passagens de volta. (Soraya Novaes da Silva, 2019).

Quando nós viajamos pra Moscou, nós tivemos. Nós tivemos uma ajuda de custo que era tipo assim, equivalente a 400 dólares; 400 dólares quando transformava em rubros, era o triplo. Pra você ter uma ideia, 50 rubros, um dólar equivale a 50 rubros. Então a gente tinha dinheiro de milionário lá. Dava pra comprar um carro, o que quisesse. Na época a gente fazia a festa, todas as atletas. Então assim, era um incentivo bom. (Maria Aparecida dos Santos, 2018).

O intuito aqui não é desvendar qual informação é verdadeira, mas chamar a atenção que, ao trabalhar com a narrativa das jogadoras, "estamos lidando com uma multiplicidade de memórias fragmentadas e internamente divididas, todas, de uma forma ou de outra, ideológica e culturalmente mediadas" (Portelli, 2000, p.107). Dessa forma, a construçáo de uma memória sobre um evento perpassa as experiências individuais que as atletas vivenciaram em suas vidas, fazendo com que as lembranças sobre um mesmo fato possam ter diferentes narrativas.

Ainda nesse início de década, a equipe Incolustre/Cambé, base da seleção desde seu princípio, por falta de patrocinadores, encerra suas atividades (Baptilani, 2005). Com o seu fim, duas equipes ganham proeminência como novas bases da seleção. $\mathrm{O}$ Clube Mauá, de Sáo Gonçalo, Rio de Janeiro (Cariello, 2012; Fabiana Diniz, 2019), e o Guarulhos, da cidade de mesmo nome, Sáo Paulo (Pinda..., 1991). Ainda nesse mesmo período, Elói Zamberlam deixa o comando da seleção, assumindo em seu lugar o técnico Digenal Cerqueira, que acabou sendo o técnico mais longevo, atuando no cargo entre 1992 e 2001. Para além dessas novas configuraçóes, a seleção vinha passando pelo seu primeiro processo de renovaçáo, finalizado em 1998, quando Soraya Novaes da Silva, a última atleta integrante do grupo de 1983, deixou de ser convocada.

Esse período de renovação, na narrativa das atletas, foi o motivador para o surgimento da primeira divisão geracional da seleção. No entendimento das atletas, as jogadoras integrantes da seleção da década de 1980 fazem parte da primeira geraçáo, enquanto as convocadas na década de 1990 constituem a segunda geração.

Os anos seguintes trouxeram marcos significativos para a seleção brasileira. A primeira delas, ocorrida em 1995, foi a participação no Grupo A do Campeonato Mundial de Handebol, ocorrido na Áustria e na Hungria. Mesmo ficando na 19a posição entre 20 equipes participantes, à frente somente do Canadá no saldo total de gols, o fato de fazer parte do principal evento da modalidade, jogando contra as melhores equipes do mundo, já representava uma importante conquista para o selecionado nacional (Krastev, 2021g). 
Em 1997, no IV Campeonato Pan-Americano de Handebol, sediado em Poços de Caldas (MG), entre 29 de abril e 4 de maio (Krastev, 2021h), a seleçáo obtém de forma inédita e invicta o ouro e, assim, comprova o seu desenvolvimento ao vencer pela primeira vez uma equipe do continente norte-americano. O fato de os Estados Unidos não terem participado dessa ediçấo, e com o Canadá apresentando uma queda em suas performances, pode ter facilitado o êxito da seleçáo.

E, por fim, a mais expressiva: a medalha de ouro nos Jogos Pan-Americanos de Winnipeg, Canadá, em 1999. Esse evento, além de apontar o handebol brasileiro como uma grande potência do continente americano, também garantiu à seleçáo o acesso ao maior evento esportivo do mundo e o único que faltava em seu currículo: os Jogos Olímpicos.

\section{Considerações finais}

Ao reconstruir uma possível história da Seleção Brasileira de Handebol (19832019), a partir de diferentes documentos e da narrativa de jogadoras e sujeitos envolvidos, nos aproximamos também de elementos que marcam a história da própria modalidade no país.

O handebol foi criado na Europa e trazido pelos imigrantes alemáes na década de 1930, disseminado pelo francês Auguste Listello, em curso a professores de Educaçáo Física na década de 1950, e consolidado na década de 1970, a partir de sua entrada nos JEBs e JUBs. Tanto a ligaçấo da modalidade com as influências europeias quanto sua vinculação ao esporte educacional permeiam fortemente o desenvolvimento da modalidade, a trajetória das jogadoras e consequentemente da seleção. Além disso, esses dois elementos nos ajudam a compreender os percursos trilhados pela seleção em busca de sua excelência e reconhecimento.

Por meio dos documentos e das narrativas, foi possível mostrar que a constituição do primeiro elenco se deu motivada pela criaçáo do Campeonato Sul-Americano de Handebol que, nesse momento, classificava para o Pré-Olímpico.

Em nível de competiçóes continentais - Campeonato Sul-Americano de Handebol, Jogos Sul-Americanos, Campeonato Pan-Americano de Handebol e Jogos Pan-Americanos -, a seleção não encontrou grandes dificuldades em garantir sua hegemonia perante os demais países participantes. Todavia, essa posição não era representativa de um handebol bem desenvolvido e estruturado nacionalmente, assim como não era suficiente em se tratando dos principais eventos da modalidade: $\mathrm{o}$ Campeonato Mundial de Handebol e os Jogos Olímpicos.

Desde o seu surgimento (1983) até sua entrada nos Jogos Olímpicos de Sydney (2000), a trajetória da seleção é marcada por um total amadorismo, infraestrutura 
precária e escassos investimentos. Essa conjuntura é reflexo de como se organizava a modalidade nacionalmente, uma vez que todos os sujeitos envolvidos - jogadoras, comissão técnica, arbitragem e gestão - baseavam suas experiências dentro dessa lógica. Nesse período, o handebol contava com competiçóes desde as categorias de base até a adulta, sendo fomentada, quase que exclusivamente, pelo esporte educacional.

Entretanto, a forte e dependente ligação que a modalidade encontrava no esporte educacional para fomentar a categoria adulta, dificultava uma maior dedicação ou uma dedicação exclusiva ao handebol.

Esse cenário, ao mesmo tempo em que fomenta a manutenção e o desenvolvimento da modalidade na fase adulta das atletas, em contraponto, acabava impossibilitando a ascensão técnica e tática dos campeonatos nacionais, pois as atletas dividiam seu tempo de treinos e competiçóes com estudos e, em muitos casos, com trabalho. A mesma situação se aplicava aos técnicos que, em sua maioria, dividiam seu tempo com atividades docentes e/ou outros trabalhos no campo esportivo.

Por fim, ao analisar os silêncios da trajetória da Seleção Brasileira de Handebol, esperamos contribuir para a sua visibilidade, assim como para a preservação da memória das jogadoras que fazem essa história.

\section{Referências}

ALBERTI, Verena. Manual de História Oral. Rio de Janeiro: FGV, 2010.

AS ESTRELAS brasileiras na luta pelas medalhas. O Globo, Rio de Janeiro, p. 50, 9 ago. 1987.

BAPTILANI, Viviane. A história e as conquistas da gloriosa equipe de handebol feminino adulto Incolustre/Cambé de 1984 a 1991. Monografia (Graduação em Educação Física) - Universidade Estadual de Londrina, Londrina, PR, 2005.

BRASIL é $1^{\circ}$ no handebol. O Estado de São Paulo, São Paulo, 15 nov. 1983a. Esporte.

BRASIL já é líder no handebol. O Estado de São Paulo, São Paulo, 12 nov. 1983b. Esporte.

CARIELLO, Gabriel. Handebol feminino do Clube Mauá completa 30 anos. O Globo, Rio de Janeiro, 16 jun. 2012.

DIAS, Eliane Alvim. [Correspondência]. Olá Shyko. Destinatário: Francisco de Assis Farias. Londrina, 30 jan. 1989.2 p.

FELIPPE, William; CALDAS, Luiz Felipe. CBHb 41 anos. Live no Instagram, 22 jun. 2020.

FERREIRA, Marieta de Moraes; AMADO, Janaína(Org.). Usos \& abusos da história oral. Rio de Janeiro: Fundação Getúlio Vargas, 1996.

HANDEBOL: o Brasil abre o torneio. O Estado de São Paulo, 9 nov. 1983. Esporte.

HANDEBOL. O Estado de São Paulo, São Paulo, 5 nov. 1983a. Esporte. 
HANDEBOL. O Estado de São Paulo, São Paulo, 11 nov. 1983b. Esporte.

HUBNER, Edgar; REIS, Cláudio. Handebol. In: DACOSTA, Lamartine Pereira (Org.). Atlas do Esporte no Brasil. Rio de Janeiro: Confef, 2005. p. 281-284.

KRASTEV, Todor. Women Handball I South American Championship 1983. 2021a. Disponível em: http://www.todor66.com/handball/America/Women_SA_1983.html. Acesso em: 12 set. 2021.

KRASTEV, Todor. Women Handball II South American Championship 1984. 2021b. Disponível em: http://www.todor66.com/handball/America/Women_SA_1984.html. Acesso em: 12 set. 2021.

KRASTEV, Todor. Women Handball I Panamerican Championship 1986. 2021c. Disponível em: http://www.todor66.com/handball/America/Women_1986.html. Acesso em: 12 set. 2019.

KRASTEV, Todor. Women Handball III South American Championship 1986. 2021d. Disponível em: http://www.todor66.com/handball/America/Women_SA_1986.html. Acesso em: 12 set. 2021.

KRASTEV, Todor. Women Handball World Championship 1987. 2021e.Disponível em: http:// www.todor66.com/handball/World/Women_B_1987.html. Acesso em: 12 set. 2021.

KRASTEV, Todor. Women Handball World Championship 1989. 2021f. Disponível em: http:// www.todor66.com/handball/World/Women_B_1989.html. Acesso em: 12 set. 2021.

KRASTEV, Todor. Women Handball World Championship 1995. 2021g. Disponível em: http:// www.todor66.com/handball/World/Women_1995.html. Acesso em: 12 set. 2021.

KRASTEV, Todor. Women Handball IV Panamerican Championship 1997. 2021h. Disponível em: http://www.todor66.com/handball/America/Women_1997.html. Acesso em: 12 set. 2021.

PINDA e Guarulhos fazem final hoje. Folha de São Paulo, São Paulo, 11 jul. 1991.

PORTELLI, Alessandro. O massacre de Civitella Val do Chiana. In: FERREIRA, Marieta de Moraes; AMADO, Janaína (Org.). Usos e abusos da história oral. Rio de Janeiro: FGV, 2000. p.103-130.

REIS, Heloisa Helena Baldy dos; GRECO, Pablo Juan; MENEZES, Rafael Pombo. Handebol: uma nova proposta metodológica. Paulínia: AutorEsporte, 2018. E-book.

SUELI faz pesadas críticas ao técnico William Felipe. Folha de São Paulo, São Paulo, 18 nov. 1983. Esportes.

THOMPSON, Paul. A voz do passado: história oral. Rio de Janeiro: Paz e Terra, 1992.

\section{Fontes orais}

BALAN, Elza Giovanelli [55]. [mar. 2019]. Entrevistadora: Suélen de Souza Andres. Belo Horizonte, MG, 27 mar. 2019. 
DINIZ, Fabiana [40]. [jun. 2019]. Entrevistadora: Suélen de Souza Andres. Belo Horizonte, MG, 13 jun. 2019.

FARIAS, Francisco de Assis (Shyko) [74]. [jul. 2019]. Entrevistadora: Suélen de Souza Andres. Belo Horizonte, MG, 17 jul. 2019.

PIORESAN, Margareth [65]. [set. 2015]. Entrevistadoras: Luiza Aguiar dos Anjos e Suélen de Souza Andres. Salvador, BA, 8 set. 2015.

SALES, Maria José Batista [52]. [dez. 2018]. Entrevistadora: Suélen de Souza Andres. Vassouras, RJ, 5 maio 2018.

SANTOS, Maria Aparecida dos [55]. [out. 2018]. Entrevistadora: Christiane Garcia Macedo. Petrolina, PE, 2 out. 2018.

SILVA, Soraya Novaes da [60]. [jul. 2019]. Entrevistadora: Suélen de Souza Andres. Belo Horizonte, MG, 12 jul. 2019.

Recebido em 01/05/2021.

Aprovado em 12/07/2021.

Contribuiçóes das autoras: Andres: planejamento da pesquisa, realização de entrevistas, análise dos dados e redação;

Goellner: orientação, redação e revisão.

Certificado de Apresentaçáo de Apreciaçáo Ética (CAAE): Comitê de Ética da UFRGS: 2007710.

Fonte de financiamento: Coordenação de Aperfeiçoamento de Pessoal de Nível Superior (Capes) - Bolsa.

Conflitos de interesse: nada a declarar. 